\section{OBSERVACIONES QUE SURGEN DEL RECIENTE DESASTRE EN EL VOLCÁN DE FUEGO, 2018, GUATEMALA}

Luis Ernesto Romano ${ }^{1, *}$

\section{INTRODUCTION}

El 3 de junio de 2018 se registró una nueva erupción del Volcán de Fuego en Guatemala, una elevación de más 3700 m.s.n.m. en cuyas faldas se desarrolla una intensa actividad agropecuaria y donde pueden encontrarse una amplia diversidad de cabeceras municipales, pueblos, aldeas, comunidades, pequeños asentamientos humanos aislados así como empresas industriales y terciarias de toda escala. Un importante porcentaje de estos asentamientos humanos se ubican en partes altas del citado volcán, donde predominan las plantaciones de café de altura y estricta altura.

Un escenario de esta índole explica las pérdidas y daños asociados a la mencionada erupción que incluyen 114 personas fallecidas, 197 desaparecidas, más de 3.200 albergadas y un estimado de 1,7 millones de personas afectadas en diferente grado (la mayoría indirectamente), de acuerdo a datos oficiales divulgados diez días después del desastre.

Las acciones desplegadas por las instituciones encargadas del monitoreo, alerta y primera respuesta han evidenciado - de nueva cuenta- debilidades en la cadena de transmisión de información e instrucciones y en la respuesta operativa en los niveles central, municipal y comunitario. Esto a pesar de que en el pasado reciente diversas iniciativas han promovido medidas de preparación en las comunidades aledañas al citado volcán, entre ellas las comprendidas dentro del proyecto BOSAI (fase 1 2009-2012)' , otra iniciativa de la Coordinadora Nacional para la Reducción de Desastres (CONRED) en $2013^{2}$ y, más recientemente, en el ejercicio de simulación a gran escala desarrollado por la misma CONRED en el marco del ejercicio "Fuerzas Aliadas Humanitarias (FAHUM)" 2018 el cual fue desarrollando suponiendo un escenario de erupción del Volcán de Fuego ${ }^{3}$.

Las reflexiones que pueden surgir de este nuevo trágico episodio de desastre en Guatemala son diversas y numerosas atendiendo a tres diferentes momentos: la situación prevalente antes del desastre; la alerta y respuesta; y el pos desastre donde se abren oportunidades para atender los retos más urgentes para la reducción del riesgo y el mejoramiento continuo de las capacidades de respuesta inmediata. A continuación se presenta un conjunto de elementos para analizar lo ocurrido e identificar posibles medidas prospectivas.

\section{ELEMENTOS PREVALECIENTES}

1. Complejidad del escenario. Al igual que muchos otros edificios volcánicos alrededor del mundo con suelos volcánicos enriquecidos y clima templado, el Volcán de Fuego alberga una intensa actividad humana evidente en la agricultura, ganadería, industria, turismo y numerosos asentamientos humanos entre comunidades, pueblos y ciudades. De acuerdo a Eddy Sánchez, director del Instituto de Sismología, Vulcanología y Meteorología (INSIVUMEH), en los flancos suroriental y suroccidental del volcán -a su juicio las zonas más vulnerables-se localizan aproximadamente 50 comunidades; mientras que, por su parte, información de CONRED establece que existen al menos 100,000 personas en constante peligro por la actividad del Volcán de Fuego ${ }^{4}$. En un escenario económico, social y ambiental como el descrito inevitablemente la población resultará fuertemente impactada por una erupción volcánica; sin embargo, siempre es posible salvaguardar vidas y reducir el sufrimiento humano con una adecuada gestión de las emergencias y desastres recurrentes.
1. Consultor independiente. San Salvador, El Salvador.

*Autor de correspondencia: lromanomartinez@yahoo. com

\section{RECIBIDO}

25 de enero de 2019

PUBLICADO

1 de julio de 2019

\section{Formato cita}

Recomendada (APA): Romano, L.E. (2019). 14 observaciones que surgen del reciente desastre en el Volcán de Fuego, 2018, Guatemala. Revista de Estudios Latinoamericanos sobre Reducción del Riesgo de Desastres REDER, 3(1), pp.109-112.

\section{() $(\mathbb{N} \otimes$}

Todos los artículos publicados en REDER siguen una política de Acceso Abierto y se respaldan en una Licencia CreativeCommons Atribución-NoComercial 4.0 Internacional.

Revista de Estudios Latinoamericanos sobre Reducción del Riesgo de Desastres (REDER)

Diseño: Lupe Bezzina Tipografía: Hospital 
2. Los preparativos piloto para alerta y respuesta de CONRED. Algunas comunidades en riesgo han sido previamente organizadas y preparadas para casos de desastre, especialmente una erupción volcánica ${ }^{5}$, mientras que -como se anotó antes- en el plano de la institucionalidad nacional y centroamericana se desarrolló el simulacro FAHUM en abril 2018, precisamente bajo el escenario supuesto de una erupción del Volcán de Fuego. Casi 20 años han transcurrido desde que se intensificaron los esfuerzos por fortalecer las capacidades de los gobiernos centroamericanos para responder ante emergencias y desastres, lamentablemente episodios recurrentes en todos los países continúan apuntando a que hacen falta otras estrategias y más financiamiento gubernamental para acometer tal tarea de forma realista y efectiva.

3. Marcada debilidad institucional. Guatemala es el único país de la región centroamericana que no ha reformado su ley relativa a la protección civil, la Ley de Creación de CONRED data de 1996 y no responde a los retos de vincular la protección civil con la necesaria gestión sostenible de los sistemas humanos y naturales desde una óptica integral, con consideraciones económicas, sociales, tecnológicas y ambientales. La CONRED aunque es una institución altamente organizada y especializada, carece de la competencia legal y los recursos financieros, humanos y materiales necesarios para dar una respuesta integral a los desastres recurrentes que se suscitan en Guatemala, principalmente porque no recibe el presupuesto necesario para una tarea de esta envergadura pero también porque exhibe altos niveles de centralización, autoritarismo y un enfoque reactivo. llustra esta situación el hecho de que, incluso en situaciones de desastres consumados y grandes necesidades humanitarias, el gobierno de Guatemala a través de su presidente, Jimmy Morales, expresa carecer de los recursos específicos para la respuesta humanitaria ${ }^{6}$.

4. El riesgo aceptable para la población y la débil organización local. La exposición a la amenaza volcánica puede llegar a insensibilizar a la población frente a peligros inminentes al grado que, de acuerdo a testimonios de los mismos pobladores, percibieron un incremento en la actividad volcánica pero les pareció que entraba dentro de la 'normalidad'". Esto refleja, por un lado, una estrategia de vida donde el riesgo aceptable o tolerable para una familia es mucho mayor al que podría ser aceptado por un grupo familiar urbano e inhibe la implementación de medidas extremas pero necesarias como la evacuación inmediata. A lo anterior se añaden los riesgos de delincuencia oportunista y la posibilidad de perder sus bienes para configurar una mentalidad donde una evacuación inmediata simplemente no es una opción. Ha resultado evidente también de que los programas de preparativos previamente realizados en el volcán fueron pilotajes, prácticamente de carácter demostrativo considerando la existencia de más de 50 comunidades dispersas en la zona de impacto volcánico potencial ${ }^{8}$.

\section{ELEMENTOS EMERGENTES}

5. Contradicciones institucionales entre CONRED e INSIVUMEH. Desde el inicio se evidenció una deficiente comunicación y diferentes formas de interpretar la información por parte de ambos entes. En lo fundamental, la discrepancia radica en las implicaciones de los boletines de monitoreo para los efectos de evacuación, mientras CONRED argumenta que el boletín emitido no lo implicaba, INSIVUMEH sostiene lo contrario. Esto dejará de ser una discusión estéril solo si conduce al establecimiento de nuevos protocolos y procedimientos más efectivos de comunicación y toma de decisiones entre estos entes.

6. Complicaciones para la búsqueda y rescate. Por la naturaleza volcánica del evento, las operaciones de rescate son probablemente las más complejas que pueden enfrentar los equipos de búsqueda y rescate puesto que se enfrentan a peligros como nubes ardientes, flujos y bombas piroclásticas, lahares y lluvia acida, entro otros peligros. Incluso días después de la erupción la temperatura de los materiales volcánicos impide la presencia humana en las zonas de desastre con el consecuente retraso para una respuesta humanitaria digna y cerrar la fase de atención de la emergencia.

1. Ver nota: "Comunidades del emergencia", disponible en: https:// www.conred.gob.gt/www/index. php?option=com_content\&view article\&id $=4154$ : comunidades-delvolcan-fuego-validan-protocolos-deemergencia\&catid $=35 \&$ Itemid $=1008$

2. Ver nota: "Comunidades aledañas al Volcán de Fuego participarán en simulacro", disponible en: https:// www.conred.gob.gt/www/index. php?option=com_content\&view=arti cle\&id=3184:comunidades-aledanasal-volcan-de-fuego-participaran-ensimulacro\&catid $=35 \&$ Itemid $=1008$

3. Ver nota periodística: "Simulacro de Fuerzas Aliadas Humanitarias por erupción del volcán de Fuego será sobre escenarios". Diario de Centroamérica, 16 de abril 2018. Guatemala. Disponible en: https://dca.gob.gt/noticiasguatemala-diario-centro-america/ simulacro-de-fuerzas-aliadashumanitarias-por-erupcion-delvolcan-de-fuego-sera-sobreescenarios/

4. Ver nota periodística: "Autoridades no tienen censo de población afectada por Volcán de Fuego". Prensa Libre. 12 de junio 2018. Guatemala. Enlace: http://www.prensalibre.com/ guatemala/comunitario/autoridadesno-tienen-censo-de-la-poblacionafectada-por-volcan-de-fuego

5. Ver nota: "Comunidades del volcán de Fuego validan protocolos de emergencia", en https://www. conred.gob.gt/www/index. php?option=com_content\&view= article\&id $=4154$ : comunidades-delvolcan-fuego-validan-protocolos-deemergencia\&catid $=35 \&$ Itemid $=1008$

6. Ver nota periodística: "Jimmy Morales: 'La Ley de presupuesto no contempla que el Estado pueda gastar un centavo en desastres' ". http://plazapublica.com.gt/content/ jimmy-morales-la-ley-de-presupuestono-contempla-que-el-estado-puedagastar-un-centavo-en

7. Ver nota periodística: "No estábamos preparados para la erupción del Volcán de Fuego". http:// www.eluniversal.com.mx/mundo/ no-estabamos-preparados-para-laerupcion-del-volcan-de-fuego 8. Idem. 
7. Capitalización política del desastre. El Congreso de Guatemala aprovechó la coyuntura para introducir cuestionables proyectos de ley que anteriormente habían enfrentado gran oposición por parte de la sociedad guatemalteca9 (entre ellos reformas al Código Penal relativas al financiamiento ilícito que reducen las penas) y que reiteran la baja prioridad que la fuerzas políticas otorgan a la problemática de los desastres, algo ya evidenciado en la reticencia para actualizar el marco jurídico e institucional en concordancia con la lacerante realidad de incremento en los impactos de desastres socio-naturales.

8. Repetición de problemas logísticos para la respuesta. Deficiencias en términos de organización local resultaron evidentes, puesto que la mayoría de comunidades aledañas al volcán no han recibido la formación y equipamiento adecuados, ni tampoco se contaba en la zona con los recursos estatales necesarios para ofrecer una respuesta adecuada para una emergencia de tal envergadura. Así las cosas, aunque hubiera existido la decisión de la población de evacuar, los medios de transporte habrían sido insuficientes.

9. Ausencia de prácticas que viabilicen la recepción, clasificación y distribución de la ayuda humanitaria. Se evidenció que la canalización de ayuda nacional e internacional no siempre fue posible durante los primeros días posteriores debido a que no se previeron adecuadamente los mecanismos de recepción, clasificación, almacenaje y distribución o, cuando menos, no se observaron ágilmente los protocolos existentes, incluso a nivel del Ministerio de Relaciones Exteriores ${ }^{10}$.

\section{RETOS}

10. Reconstrucción mejorada. Una de las reiteraciones de este desastre, es que la población más desfavorecida habita en lugares donde simplemente no deberían permitirse asentamientos humanos: la realidad es que las necesidades de sobrevivencia en un contexto de exclusión social orillan a gran parte de la población a convivir con el peligro. La reconstrucción en este y todos los casos, enfrenta el reto de ofrecer a la población afectada una solución habitacional segura, no expuesta a amenazas de alto nivel.

11. Identificación de aprendizajes. Es fundamental identificar los retos que -a veinte años de práctica- enfrentan los proyectos y programas, tanto gubernamentales como no gubernamentales, para mejorar su efectividad y sostenibilidad. Esta es una nueva oportunidad para una discusión seria sobre la reforma del sistema de reducción de desastres de Guatemala, el cual ha mostrado de sobra sus límites y tiene deficiencias evidentes que pueden ser subsanadas con decisiones políticas que favorezcan propuestas concretas de reforma ya existentes que pueden continuar refinándose.

12. Elaboración, difusión y adopción de protocolos de monitoreo, alerta y respuesta. No está claro si existen o no planes y/o protocolos de actuación comunitarios, municipales o nacionales, específicos para el Volcán de Fuego. De acuerdo a CONRED, anteriormente dos comunidades validaron protocolos, pero en todo caso, es evidente que hace falta una apropiación local y una mayor escala de acción comunitaria. El fortalecimiento de capacidades locales puede impulsarse aún más de lo hecho hasta ahora mediante procesos de elaboración participativa de procedimientos de monitoreo, alerta y respuesta comunitarios que abonen a la construcción de una cultura local de convivencia sostenible con los peligros volcánicos. Salvando las diferencias educativas, económicas y de logística disponible, el caso de la evacuación exitosa de un hotel y campo de golf en la zona de impacto contrasta con la inacción de prácticamente todas las comunidades en riesgo en el momento crítico de la alerta y es una prueba fehaciente de que es posible una reacción exitosa de salvaguarda de la integridad humana aún en caso de desastres detonados por actividad volcánica súbita"

13. Reforma legal e institucional del Estado. La discusión de una nueva ley para la gestión de riesgos y desastres debe reactivarse para dar paso a la elaboración, propuesta, negociación y adopción de nuevas disposiciones institucionales, administrativas y financieras que mejoren el desempeño de Estado y sociedad en la compleja tarea de reducir el impacto de desastres. Un elemento fundamental que, paradójicamente, siempre se soslaya es la adecuación de las finanzas del Estado (gobiernos central y

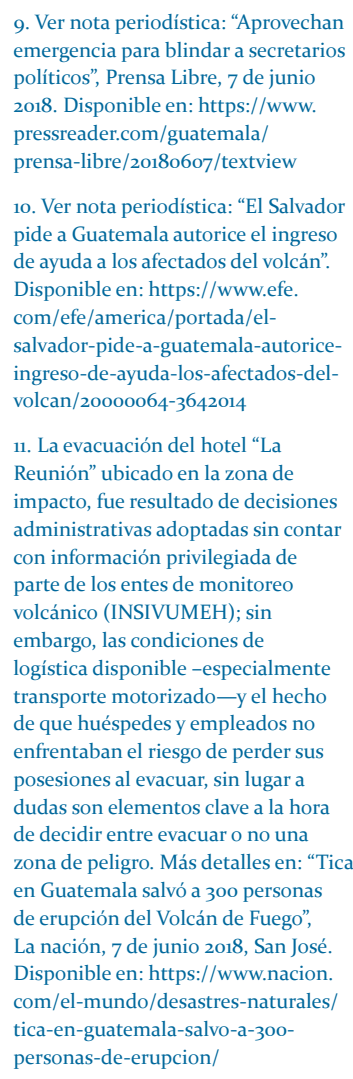

9. Ver nota periodística: "Aprovechan emergencia para blindar a secretarios políticos", Prensa Libre, 7 de junio 2018. Disponible en: https://www. pressreader.com/guatemala/ prensa-libre/20180607/textview

10. Ver nota periodística: "El Salvador pide a Guatemala autorice el ingreso de ayuda a los afectados del volcán". Disponible en: https://www.efe. com/efe/america/portada/elsalvador-pide-a-guatemala-autoriceingreso-de-ayuda-los-afectados-delvolcan/20000064-3642014

11. La evacuación del hotel "La Reunión" ubicado en la zona de impacto, fue resultado de decisiones administrativas adoptadas sin contar con información privilegiada de parte de los entes de monitoreo volcánico (INSIVUMEH); sin embargo, las condiciones de logística disponible -especialmente transporte motorizado-y el hecho de que huéspedes y empleados no enfrentaban el riesgo de perder sus posesiones al evacuar, sin lugar a dudas son elementos clave a la hora de decidir entre evacuar o no una zona de peligro. Más detalles en: "Tica en Guatemala salvó a zoo personas de erupción del Volcán de Fuego", La nación, 7 de junio 2018, San José. Disponible en: https://www.nacion. com/el-mundo/desastres-naturales/ tica-en-guatemala-salvo-a-30opersonas-de-erupcion/ 
municipales) para sufragar iniciativas de gestión de riesgos y respuesta a desastres, una medida que debe necesariamente complementarse con una adecuada previsión de los impactos y medidas compensatorias de proyectos de inversión pública y privada.

14. Fortalecimiento de capacidades locales y municipales. Está claro que la respuesta en el nivel nacional del sistema para la reducción de desastres en Guatemala no está a la altura de las necesidades que la respuesta a un desastre local de mediana o gran envergadura exige, tarea que necesariamente requiere de una respuesta local inmediata y pertinente. Por lo anterior, el fortalecimiento de las estructuras municipales y comunitarias ya contempladas en la Ley de la CONRED deberá retomarse con mayor énfasis y continuidad, sin necesidad de esperar una reforma 0 actualización de la citada Ley.

La prevalencia de la vulnerabilidad generalizada en las comunidades del Volcán de Fuego es reflejo de una realidad que trasciende a todo el territorio de Guatemala, y de más de un centenar de países en vías de desarrollo. Estas comunidades se han configurado a través de procesos históricos de exclusión económica y social, y de ocupación de zonas de peligro. Esto no obsta, empero, para aspirar a comunidades más seguras a través de procesos de inversión económica y social, las cuales solo son posibles propugnando por una reforma del Estado que favorezca la transformación social de las condiciones locales de riesgo.

Existen experiencias exitosas de transformación que evidencian la posibilidad de una efectiva reducción del riesgo e impacto de los desastres, lo que se requiere es la decisión política para destinar los recursos financieros, humanos y materiales necesarios, así como también la adopción de criterios para que las nuevas inversiones consideren medidas de mitigación de impactos sobre el riesgo y para su propia sostenibilidad. 